\title{
Milstein Scheme Applied to Stochastic Point Kinetics
}

\author{
${ }^{1}$ Daniel Suescún-Díaz, ${ }^{1}$ Daniel E. Cedeño-Girón and ${ }^{2}$ D. Peña Lara \\ ${ }^{1}$ Departamento de Ciencias Naturales, Universidad Surcolombiana, Av. Pastrana, \\ Neiva, Huila, Colombia \\ ${ }^{2}$ Departamento de Física, Universidad del Valle, A.A 25360, Cali, Colombia
}

\begin{abstract}
The Milstein's iterative scheme is presented for the solution of stochastic point equations which are a set of non-linear and strongly coupled stochastic differential equations. The proposed method considers an attenuation factor in the covariance matrix and an approximation to the derivative of the covariance matrix. The implementation is carried out under different initial conditions, several groups of precursors, time steps and constant reactivities. The results are accurate in the calculation of the mean values for neutron density and concentration of precursors compared with other methods reported in the literature.
\end{abstract}

$\underline{\text { Key words: Nuclear reactors, stochastic point kinetic equations, Milstein scheme, neutron population, density }}$

\section{INTRODUCTION}

The production of nuclear energy is carried out in a nuclear reactor based on a controlled chain reaction of heavy materials such as some isotopes of uranium or plutonium by processes named nuclear fission, that will occur in the atomic nucleus of the isotope of these elements. Nuclear reactors allow the production and maintenance of nuclear fission in a controlled manner, guaranteeing the production of energy (Stacey, 2018).

The dynamics of the nuclear reactor are physically described by the point kinetics equations which facilitate the understanding of the temporary evolution of parameters such as neutron density, concentration of precursors and reactivity. However, these equations are deterministic, therefore, they do not involve the random and probabilistic nature of the events that modify the neutron population in the reactor core. Therefore, a need to perform a statistical study of this physical system based on stochastic differential equations, thus, resulting in stochastic point kinetics (Hayes and Allen, 2005):

$$
\frac{\mathrm{d}}{\mathrm{dt}}|\mathrm{P}(\mathrm{t})=\mathrm{A}| \mathrm{P}(\mathrm{t})+\left|\mathrm{Q}(\mathrm{t})+\mathrm{B}^{1 / 2} \frac{\mathrm{d}}{\mathrm{dt}}\right| \omega(\mathrm{t})
$$

where, $|\mathrm{P}(\mathrm{t})\rangle$ is the vector of random variables defined by Eq. 2, A is the matrix of expected values defined in Eq. 3, $|\mathrm{Q}(\mathrm{t})\rangle$ is the source vector defined in equation, $B$ is the covariance matrix defined in Eq. 5, $|\omega(\mathrm{t})\rangle$ is the Wiener process vector defined in Eq. 6 or by $\sqrt{\Delta t} \mid \eta$, these are continuoustime stochastic processes with statistically independent and stationary increases, not differentiable in time:

$$
\begin{gathered}
P(\mathrm{t})=\left[\begin{array}{c}
\mathrm{n}(\mathrm{t}) \\
\mathrm{C}_{1}(\mathrm{t}) \\
\mathrm{C}_{2}(\mathrm{t}) \\
\vdots \\
\mathrm{C}_{\mathrm{m}}(\mathrm{t})
\end{array}\right] \\
\mathrm{A}=\left[\begin{array}{ccccc}
\frac{\rho(\mathrm{t})-\beta}{\Lambda} & \lambda_{1} & \lambda_{2} & \cdots & \lambda_{\mathrm{m}} \\
\frac{\beta_{1}}{\Lambda} & -\lambda_{1} & 0 & \cdots & 0 \\
\frac{\beta_{2}}{\Lambda} & 0 & -\lambda_{2} & \cdots & 0 \\
\vdots & \vdots & \vdots & \ddots & \vdots \\
\frac{\beta_{\mathrm{m}}}{\Lambda} & 0 & 0 & \cdots & -\lambda_{\mathrm{m}}
\end{array}\right] \\
\\
\quad \mathrm{Q}(\mathrm{t})=\left[\begin{array}{c}
\mathrm{q}(\mathrm{t}) \\
0 \\
0 \\
\vdots \\
0
\end{array}\right]
\end{gathered}
$$

Corresponding Author: Daniel Suescún-Díaz, Departamento de Ciencias Naturales, Universidad Surcolombiana, Av. Pastrana, Neiva, Huila, Colombia 
where, $\mathrm{n}$ is the density of neutrons, $\mathrm{C}_{\mathrm{m}}$ is the concentration of precursors of $\mathrm{m}+1$ group, $\rho$ is the reactivity which accounts for the production of neutrons, $\beta$ is the total fraction of delayed neutron precursors, $\Lambda$ is the average neutron generation time, $\lambda_{\mathrm{m}}$ is the decay constant of class $\mathrm{m}$ of delayed neutron precursors, $\mathrm{q}$ is the magnitude of the external neutron source, $\omega_{\mathrm{m}}$ are Wiener processes that are characterized by stochastic processes of continuous time and independent stationary increments. The elements of matrix B are described as follows:

$$
\begin{gathered}
\xi=\gamma \mathrm{n}(\mathrm{t})+\sum_{\mathrm{i}=1}^{\mathrm{m}} \lambda_{\mathrm{i}} \mathrm{C}_{\mathrm{i}}(\mathrm{t})+\mathrm{q}(\mathrm{t}) \\
\gamma=\frac{-1-\rho+v(1-\beta)^{2}+2 \beta}{\Lambda} \\
\mathrm{a}_{\mathrm{m}}=\frac{\beta_{\mathrm{m}}[v(1-\beta)-1]}{\Lambda} \mathrm{n}(\mathrm{t})-\lambda_{\mathrm{m}} \mathrm{C}_{\mathrm{m}}(\mathrm{t}) \\
\mathrm{r}_{\mathrm{m}}=\frac{\nu \beta_{\mathrm{m}}^{2}}{\Lambda} \mathrm{n}(\mathrm{t})+\lambda_{\mathrm{m}} \mathrm{C}_{\mathrm{m}}(\mathrm{t}) \\
\mathrm{b}_{\mathrm{i}, \mathrm{j}}=\frac{\nu \beta_{\mathrm{i}-1} \beta_{\mathrm{j}-1}}{\Lambda} \mathrm{n}(\mathrm{t})
\end{gathered}
$$

where, $v$ is the average number of neutrons generated per fission event. Equation 1 corresponds to stochastic point kinetics and consists mathematically of a set of $m+1$ nonlinear and strongly coupled stochastic differential equations of Itô, involving $\mathrm{m}+2$ random variables (neutron density, $\mathrm{m}$ precursor groups and reactivity). The aforementioned reveals a nonexistent analytical solution of the system of equations. However, an approximate numerical solution is possible by iterative schemes. In this work we propose Milstein's iterative scheme that originated from the truncation of the expansion of the Itô-Taylor series, this expansion being a generalization of the well-known Taylor series. The Milstein scheme is obtained by truncate the Itô-Taylor expansion and has a convergence order of 1.0 (Kloeden and Platen, 1992).

It is important to note that for B in Eq. 1, deterministic point kinetics is obtained; therefore, Eq. 1 is considered as a model that generalizes the point kinetics equation.

\section{MATERIALS AND METHODS}

Milstein's scheme: The iterative scheme proposed in this study is obtained by truncating the expansion of
Itô-Taylor in the fourth term and is named Milstein. The Milstein scheme written in discrete form can be seen in Eq. 12. It should be noted that if $b=0$, Euler's deterministic scheme is obtained, the Milstein scheme is therefore considered to be a generalization of the Euler scheme, in addition to having the same order of convergence (1.0) (Kloeden and Platen, 1992):

$$
\mathrm{x}_{\mathrm{n}+1}=\mathrm{x}_{\mathrm{n}}+\mathrm{a}_{\mathrm{n}} \Delta+\mathrm{b}_{\mathrm{n}} \Delta \omega+\frac{1}{2} \mathrm{~b}_{\mathrm{n}} \frac{\partial}{\partial \mathrm{x}_{\mathrm{n}}} \mathrm{b}_{\mathrm{n}}\left[(\Delta \omega)^{2}-\Delta\right]
$$

Where:

$$
\begin{gathered}
\Delta=\mathrm{t}_{\mathrm{n}+1}-\mathrm{t}_{\mathrm{n}} \\
\Delta_{\omega}=\omega_{\mathrm{n}+1}-\omega_{\mathrm{n}}
\end{gathered}
$$

Equation 14 presents a Wiener process. This is characterized as being a continuous time stochastic process of independent stationary increments, $\omega_{\mathrm{t}=0}=0$ with probability 1 and $\omega_{\mathrm{t}}-\omega_{\mathrm{s}} \sim \kappa(0, \mathrm{t}-\mathrm{s})$ for $0 \leq \mathrm{s} \leq \mathrm{t}$ where, $\kappa\left(\mu, \sigma^{2}\right)$ denotes normal distribution with an expected value $\mu$ and variance $\sigma^{2}$ (Le Gall, 2016), with the property presented in Eq. 15 which is useful for simulation:

$$
\Delta \omega=\sqrt{\Delta} \aleph(0,1)
$$

Milstein in stochastic point kinetics: Applying the iterative scheme proposed in this study, described in Eq. 12, to the stochastic point kinetics described by Eq. 1, we obtain:

$$
\mathrm{P}_{\mathrm{k}+1}=\mathrm{P}_{\mathrm{k}}+\left(\mathrm{A}_{\mathrm{k}} \mathrm{P}_{\mathrm{k}}+\mathrm{Q}_{\mathrm{k}}\right) \Delta+\mathrm{B}_{\mathrm{k}}^{1 / 2} \Delta \omega_{\mathrm{k}}+\frac{1}{2} \mathrm{~B}_{\mathrm{k}}^{1 / 2} \frac{\mathrm{d}}{\mathrm{dP}_{\mathrm{k}}} \mathrm{B}_{\mathrm{k}}^{1 / 2}\left[\left(\Delta \omega_{\mathrm{k}}\right)^{2}-\Delta\right]
$$

Where:

$$
\begin{gathered}
\mathrm{P}_{\mathrm{k}}=\left[\begin{array}{c}
\mathrm{n}_{\mathrm{k}} \\
\mathrm{C}_{1 \mathrm{k}} \\
\mathrm{C}_{2 \mathrm{k}} \\
\vdots \\
\mathrm{C}_{\mathrm{mk}}
\end{array}\right] \\
\mathrm{A}_{\mathrm{k}}=\left[\begin{array}{ccccc}
\frac{\rho_{\mathrm{k}}-\beta}{\Lambda} & \lambda_{1} & \lambda_{2} & \cdots & \lambda_{\mathrm{m}} \\
\frac{\beta_{1}}{\Lambda} & -\lambda_{1} & 0 & \cdots & 0 \\
\frac{\beta_{2}}{\Lambda} & 0 & -\lambda_{2} & \cdots & 0 \\
\vdots & \vdots & \vdots & \ddots & \vdots \\
\frac{\beta_{\mathrm{m}}}{\Lambda} & 0 & 0 & \cdots & -\lambda_{\mathrm{m}}
\end{array}\right]
\end{gathered}
$$




$$
\begin{gathered}
\mathrm{Q}_{\mathrm{k}}=\left[\begin{array}{c}
\mathrm{q}_{\mathrm{k}} \\
0 \\
0 \\
\vdots \\
0
\end{array}\right] \\
\mathrm{B}_{\mathrm{k}}=\left[\begin{array}{ccccc}
\xi_{\mathrm{k}} & \mathrm{a}_{1 \mathrm{k}} & \mathrm{a}_{2 \mathrm{k}} & \ldots & \mathrm{a}_{\mathrm{ik}} \\
\mathrm{a}_{1 \mathrm{k}} & \mathrm{r}_{1 \mathrm{k}} & \mathrm{b}_{2,3 \mathrm{k}} & \ldots & \mathrm{b}_{2, \mathrm{ik}} \\
\mathrm{a}_{2 \mathrm{k}} & \mathrm{b}_{3,2 \mathrm{k}} & \mathrm{r}_{2 \mathrm{k}} & \ldots & \mathrm{b}_{3, \mathrm{k}} \\
\vdots & \vdots & \vdots & \ddots & \vdots \\
\mathrm{a}_{\mathrm{ik}} & \mathrm{b}_{\mathrm{i}, 2 \mathrm{k}} & \mathrm{b}_{\mathrm{i}, 3 \mathrm{k}} & \ldots & \mathrm{r}_{\mathrm{ik}}
\end{array}\right] \\
\\
\Delta \omega_{\mathrm{k}}=\left[\begin{array}{c}
\Delta \omega_{1 \mathrm{k}} \\
\Delta \omega_{2 \mathrm{k}} \\
\Delta \omega_{3 \mathrm{k}} \\
\vdots \\
\Delta \omega_{\mathrm{m}+1 \mathrm{k}}
\end{array}\right]
\end{gathered}
$$

As can be seen in Eq. 16 this scheme requires the derivative of the square root of the variance matrix, therefore in this research, we propose to approximate this derivative in the following way:

$$
\frac{\mathrm{d}}{\mathrm{dP}} \mathrm{B}^{1 / 2}(\mathrm{P}) \approx \frac{\mathrm{B}^{1 / 2}(\mathrm{P}+\Delta \mathrm{P})-\mathrm{B}^{1 / 2}(\mathrm{P})}{\Delta \mathrm{P}}
$$

where, $\Delta \mathrm{P}=(\mathrm{A}(\mathrm{P}) \mathrm{P}+\mathrm{Q}) \Delta+\mathrm{B}^{1 / 2}(\mathrm{P}) \Delta \omega$ this expression is the discrete version of Eq. 1, therefore, Eq. 22 can be written in the following way:

$$
\left[(\mathrm{AP}+\mathrm{Q}) \Delta+\mathrm{B}^{1 / 2}(\mathrm{P}) \Delta \omega\right] \frac{\mathrm{d}}{\mathrm{dP}} \mathrm{B}^{1 / 2}(\mathrm{P}) \approx \mathrm{B}^{1 / 2}(\mathrm{P}+\Delta \mathrm{P})-\mathrm{B}^{1 / 2}(\mathrm{P})
$$

Replacing Eq. 15 in Eq. 23, we can write:

$$
\sqrt{\Delta} \mathrm{B}^{\frac{1}{2}}(\mathrm{P}) \frac{\mathrm{d}}{\mathrm{dP}} \mathrm{B}^{\frac{1}{2}}(\mathrm{P})+\mathrm{O}(\Delta) \approx \mathrm{B}^{1 / 2}(\mathrm{P}+\Delta \mathrm{P})-\mathrm{B}^{1 / 2}(\mathrm{P})
$$

Dividing by $\sqrt{\Delta}$ Eq. 24, the following is obtained:

$$
\mathrm{B}^{\frac{1}{2}}(\mathrm{P}) \frac{\mathrm{d}}{\mathrm{dP}} \mathrm{B}^{\frac{1}{2}}(\mathrm{P}) \approx \frac{\mathrm{B}^{1 / 2}(\mathrm{P}+\Delta \mathrm{P})-\mathrm{B}^{1 / 2}(\mathrm{P})}{\sqrt{\Delta}}
$$

The iterative scheme proposed in this study given by Eq. 26 is implemented using MATLAB Software where multiple simulations are performed involving different initial conditions, groups of precursors, time steps and constant reactivities. To model the Wiener processes, the MATLAB state command was used which generates pseudo-random numbers by means of a seed which for this research is $2^{31}-1$. Since, the approximation proposed in Eq. 25 can generate greater standard deviation of the expected values for neutron density and concentration of precursors, it is proposed to attenuate this by means of a constant factor $\delta$ that multiplies the parameter $\gamma$ defined in Eq. 8, the values of $\delta$ will be $1,0.5$ and 0 . The results obtained are presented in the following section:

$$
\begin{aligned}
& \mathrm{P}_{\mathrm{k}+1} \approx \mathrm{P}_{\mathrm{k}}+\left(\mathrm{A}_{\mathrm{k}} \mathrm{P}_{\mathrm{k}}+\mathrm{Q}_{\mathrm{k}}\right) \Delta+\mathrm{B}_{\mathrm{k}}^{1 / 2} \Delta \omega_{\mathrm{k}}+ \\
& \frac{\mathrm{B}^{1 / 2}\left(\mathrm{P}_{\mathrm{k}}+\Delta \mathrm{P}_{\mathrm{k}}\right)-\mathrm{B}^{1 / 2}\left(\mathrm{P}_{\mathrm{k}}\right)}{2 \sqrt{\Delta}}\left[\left(\Delta \omega_{\mathrm{k}}\right)^{2}-\Delta\right]
\end{aligned}
$$

The following section presents the results obtained by scheme (Eq. 26) for the different values of factor $\delta$ and are compared with methods reported in the literature and with the Deterministic Model (DM).

\section{RESULTS AND DISCUSSION}

Various numerical experiments are presented, using one and six groups of different precursors, initial conditions, time steps, constant reactivities and values of the $\delta$ factor. The results obtained by the numerical experiments are compared on average with the Deterministic Model (DM) of point kinetics which is calculated by the implicit Euler scheme, since, the deterministic formulation does not have values of standard deviation in the tables represented by No Apply (NA). They will also be compared on average and standard deviation with other stochastic schemes reported in literature such as Stochastic Piecewise Constant Approximation (SPCA) and Monte Carlo (MC) (Hayes and Allen, 2005), Euler Maruyama (EM) and T 1.5 (Taylor 1.5) (Ray, 2012), Fractional Stochastic Point Kinetic Equations (FSNPK) (Ray and Patra, 2013), Simplificated Stochastic Point Kinetics Equations (SSPK) (Ayyoubzadeh and Vosoughi, 2014), Analytical Exponential Model (AEM) (Nahla and Edress, 2016), Double Diagonalization-Decomposition Method (Double DDM) (Da Silva et al., 2016), Efficient Stochastic Model (ESM) (Nahla and Edress, 2016ab), (IEM) Implicit Euler Maruyama (Suescun-Diaz et al., 2018). The values reported in the literature have been written with four significant figures, in cases where fewer numbers are reported, this has been completed with zeros.

First example: A group of precursors and the following physical parameters are considered: reactivity $\rho=-1 / 3$, time of neutron generation $\Lambda=2 / 3$, decay constant $\lambda_{1}=0.1\left(\mathrm{~s}^{-1}\right)$, fraction of delayed neutron precursors $\beta=0.05$, average of neutrons generated per fission event $v=2.5$, external neutron source $q(\mathrm{t})=200$, initial condition $n(0)=400, C(0)=300$. This example is carried out with 40 iterations in a time of [0, 2] sec using 5000 Wiener processes. Table 1 shows the density of neutrons and concentration of precursors together with their standard deviations for the different values of factor $\delta$ obtained by the stochastic model as well as the values of neutron density and the concentration of precursors of the Deterministic Model (DM). At the same time, Table 2 compares the results obtained by the proposed scheme (M) with $\delta$ equal to zero and those reported in literature. 


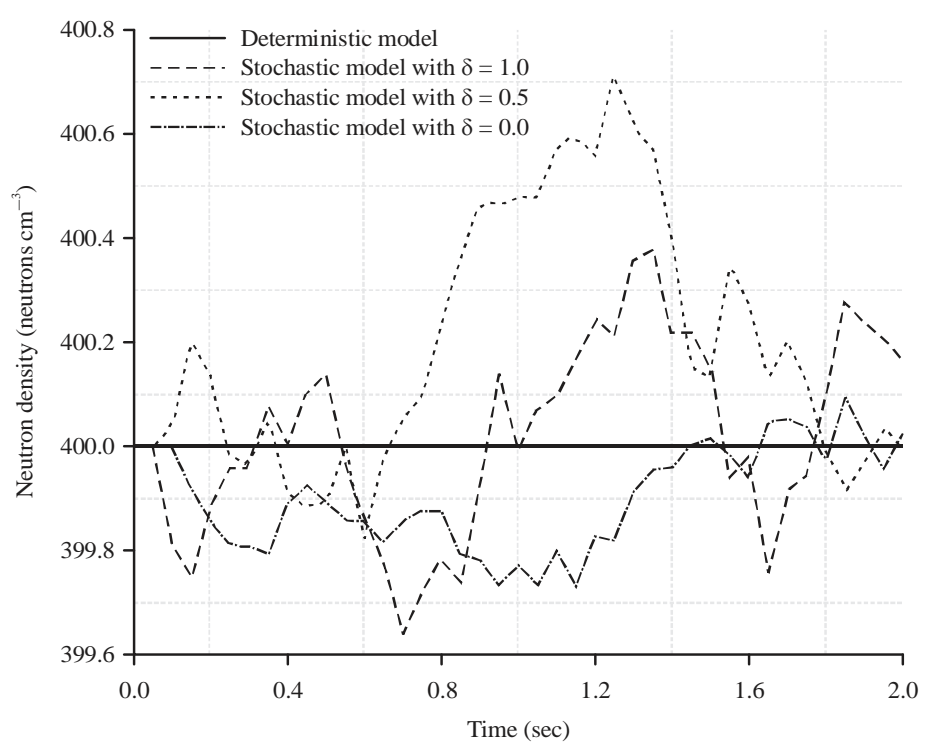

Fig. 1: Neutron density for the stochastic model for the different values of and the Deterministic Model (DM) with reactivity

Table 1: Stochastic model with different values of and Deterministic Model (MD)

\begin{tabular}{lllll}
\hline Parameters & $\mathrm{E}[\mathrm{n}(2 \mathrm{~s})]$ & $\sigma[\mathrm{n}(2 \mathrm{~s})]$ & $\mathrm{E}[\mathrm{C}(2 \mathrm{~s})]$ & $\sigma[\mathrm{C}(2 \mathrm{~s})]$ \\
\hline$\delta$ & & & & \\
1 & 400.1646 & 32.4124 & 299.9876 & 10.2709 \\
0.5 & 399.9962 & 25.4137 & 299.9674 & 10.0973 \\
0 & 400.0257 & 14.4789 & 299.7923 & 9.4074 \\
DM & 400.0000 & NA & 300.0000 & NA \\
\hline
\end{tabular}

Table 2: Comparison of results, proposed scheme, reported in the literature and deterministic model

\begin{tabular}{lllll}
\hline Method & $\mathrm{E}[\mathrm{n}(2 \mathrm{~s})]$ & $\sigma[\mathrm{n}(2 \mathrm{~s})]$ & $\mathrm{E}[\mathrm{C}(2 \mathrm{~s})]$ & $\sigma[\mathrm{C}(2 \mathrm{~s})]$ \\
\hline SPCA & 395.3200 & 29.4110 & 300.6700 & 8.3564 \\
MC & 400.0300 & 27.3110 & 300.0000 & 7.8073 \\
EM & 412.2300 & 34.3910 & 315.9600 & 8.2656 \\
T 1.5 & 412.1000 & 34.5190 & 315.9300 & 8.3158 \\
FSNPK & 412.2300 & 34.3918 & 315.9690 & 8.2656 \\
AEM & 396.2800 & 31.2120 & 300.4200 & 7.9576 \\
Double DDM & 402.3500 & 28.6100 & 305.8400 & 7.9240 \\
ESM & 396.6200 & 0.9199 & 300.3900 & 0.0016 \\
IEM & 399.7100 & 31.4310 & 299.7700 & 7.9411 \\
IEM* & 399.9874 & 0.5439 & 299.8730 & 6.8405 \\
M & 400.0257 & 14.4789 & 299.7923 & 9.4074 \\
DM & 400.0000 & NA & 300.0000 & NA \\
\hline
\end{tabular}

In Table 1, it can be seen that as the value of the attenuating factor diminishes, so does the standard deviation of the variables in the study, the most notable aspect being that for the density of neutrons where the expected value in time $\mathrm{t}=2 \mathrm{sec}$ is closer to the deterministic value; this behavior can be seen in Fig. 1. However, the expected value of the concentration of precursors moves slightly away from the deterministic value, even though its standard deviation decreases. The results obtained by the proposed scheme are in agreement with other methods reported in literature as can be seen in Table 2 with satisfactory precision in the mean value of the neutron density and the concentration of precursors and in the standard deviation. It is significant that the proposed scheme turns out to be that which comes closest to the deterministic value of neutron density but that which presents the highest standard deviation for the concentration of precursors.

For the next two examples, two groups of precursors with similar physical parameters will be considered: The generation time of neutrons $\Lambda=0.00002(\mathrm{~s})$, decay constants $\lambda_{\mathrm{i}}=[0.0127,0.0317,0.1150,0.31101 .4000$, 3.8700] $\left(\mathrm{s}^{-1}\right)$, the fraction of delayed neutron precursors of the i-th group $\beta_{i}=[0.000266,0.001491,0.001316$, $0.002849,0.000896,0.000182]$, the total fraction of delayed neutron precursors $\beta=0.007$, the average of neutrons generated per fission event $v=2.5$, external neutron source $q(\mathrm{t})=0$, initial condition:

$$
\left[\mathrm{n}(0), \mathrm{C}_{1}(\mathrm{t}), \mathrm{C}_{2}(\mathrm{t}), \ldots, \mathrm{C}_{6}(\mathrm{t})\right]^{\mathrm{T}}=100\left[1, \frac{\beta_{1}}{\lambda_{1} \Lambda}, \frac{\beta_{2}}{\lambda_{2} \Lambda}, \ldots, \frac{\beta_{6}}{\lambda_{6} \Lambda}\right]^{\mathrm{T}}
$$

and using 5000 Wiener processes. These examples represent reactivities for real nuclear reactors. The second example uses a subcritical reactivity $\rho=300 \mathrm{pcm}$ in a time of [0,0.1] sec and using 40 iterations 40 iterations while the third example uses a critical reactivity $\rho=700$ pcm in a time interval of [0,0.001] sec and using 40 iterations. Table 3 presents the density of neutrons and concentration of precursors together with their standard deviations for the different values of factor obtained for the stochastic model as well as the values of neutron density and the concentration of precursors of the Deterministic Model (DM) for the subcritical and critical reactivities. Table 4 and 5 compare the results obtained by the proposed scheme $(\mathrm{M})$ with equal to zero and those reported in literature for the subcritical and critical reactivities. 
J. Eng. Applied Sci., 15 (1): 107-113, 2020

Table 3: Stochastic model with different values of and Deterministic Model (MD) for subcritical and critical reactivities

\begin{tabular}{|c|c|c|c|c|}
\hline Methods & $\mathrm{E}$ [n (0.1s)] & $\sigma$ [n (0.1s)] & $\mathrm{E}[\mathrm{C}(0.1 \mathrm{~s})]$ & $\sigma[\mathrm{C}(0.1 \mathrm{~s})]$ \\
\hline \multicolumn{5}{|l|}{$\begin{array}{l}\boldsymbol{\rho}=\mathbf{3 0 0} \mathbf{p c m} \\
\delta\end{array}$} \\
\hline 1 & 175.2304 & 332.3661 & 4.4886 & 3.2125 \\
\hline 0.5 & 166.2755 & 210.8827 & 4.4858 & 2.1493 \\
\hline 0 & 179.9952 & 18.0870 & 4.4886 & 0.3407 \\
\hline $\mathrm{DM}$ & 179.9485 & NA & 4.4888 & NA \\
\hline $\begin{array}{l}\boldsymbol{\rho}=700 \mathrm{pcm} \\
\delta\end{array}$ & $\mathrm{E}[\mathrm{n}(0.001 \mathrm{~s})]$ & $\sigma[\mathrm{n}(0.001 \mathrm{~s})]$ & $\mathrm{E}[\mathrm{C}(0.001 \mathrm{~s})]$ & $\sigma[\mathrm{C}(0.001 \mathrm{~s})]$ \\
\hline 1 & 134.1748 & 98.5048 & 4.4636 & 30.9602 \\
\hline 0.5 & 134.3667 & 69.1494 & 4.4636 & 25.4569 \\
\hline 0 & 134.9782 & 7.6689 & 4.4636 & 14.6566 \\
\hline DM & 135.0010 & NA & 4.4636 & NA \\
\hline
\end{tabular}

Table 4: Comparison of results, proposed scheme, reported in the literature and Deterministic Model (DM) for subcritical reactivity

\begin{tabular}{|c|c|c|c|c|}
\hline Methods & $\mathrm{E}$ [n (0.1s)] & $\sigma[\mathrm{n}(0.1 \mathrm{~s})]$ & $\mathrm{E}[\mathrm{C}(0.1 \mathrm{~s})]$ & $\sigma[\mathrm{C}(0.1 \mathrm{~s})]$ \\
\hline \multicolumn{5}{|l|}{$\rho=300 \mathrm{pcm}$} \\
\hline SPCA & 186.3100 & 164.1600 & $4.4910 \mathrm{x}$ & $1.9172 \mathrm{x}$ \\
\hline MC & 183.0400 & 168.7900 & $4.4780 \mathrm{x}$ & $1.4957 \mathrm{x}$ \\
\hline EM & 208.6000 & 255.9500 & $4.4980 \mathrm{x}$ & $1.2333 x$ \\
\hline Т 1.5 & 199.4080 & 168.5470 & $4.4970 \mathrm{x}$ & $1.2188 x$ \\
\hline FSNPK & 208.5990 & 255.9540 & $4.4981 \mathrm{x}$ & $1.2333 \mathrm{x}$ \\
\hline SSPK & 184.8000 & 186.9600 & $4.4890 \mathrm{x}$ & $0.9826 x$ \\
\hline \multicolumn{5}{|l|}{$\rho=700 \mathrm{pcm}$} \\
\hline AEM & 186.3000 & 164.1400 & $4.4900 \mathrm{x}$ & $1.9119 x$ \\
\hline Double DDM & 187.0500 & 167.8300 & $4.4880 \mathrm{x}$ & $1.4756 \mathrm{x}$ \\
\hline ESM & 179.9300 & 10.5550 & 4.4890x & $0.0947 x$ \\
\hline IEM & 178.2700 & 165.1100 & $4.4886 x$ & $1.2536 \mathrm{x}$ \\
\hline IEM $^{*}$ & 179.9461 & 0.2178 & $4.4888 x$ & $0.0604 x$ \\
\hline M & 179.9952 & 18.0870 & $4.4886 x$ & 0.3407 \\
\hline DM & 179.9485 & NA & $4.4888 x$ & NA \\
\hline
\end{tabular}

Table 5: Comparison of results, proposed scheme, reported in the literature and Deterministic Model (DM) for critical reactivity

\begin{tabular}{|c|c|c|c|c|}
\hline Methods & $\mathrm{E}[\mathrm{n}(0.001 \mathrm{~s})]$ & $\sigma[\mathrm{n}(0.001 \mathrm{~s})]$ & $\mathrm{E}[\mathrm{C}(0.001 \mathrm{~s})]$ & $\sigma[\mathrm{C}(0.001 \mathrm{~s})]$ \\
\hline SPCA & 134.5500 & 91.2420 & $4.4640 \mathrm{x}$ & 19.4440 \\
\hline MC & 135.6700 & 93.3760 & $4.4640 \mathrm{x}$ & 16.2260 \\
\hline EM & 139.5680 & 92.0420 & $4.4630 \mathrm{x}$ & 6.0710 \\
\hline Т 1.5 & 139.5690 & 92.0470 & $4.4630 \mathrm{x}$ & 18.3370 \\
\hline AEM & 134.5400 & 91.2340 & $4.4640 \mathrm{x}$ & 19.2350 \\
\hline Double DDM & 135.8600 & 93.2100 & $4.4630 \mathrm{x}$ & 17.8450 \\
\hline ESM & 134.9600 & 6.8527 & $4.4640 \mathrm{x}$ & 2.5290 \\
\hline IEM & 134.0200 & 93.2730 & $4.4636 x$ & 18.7760 \\
\hline IEM* ${ }^{*}$ & 134.9218 & 5.9661 & $4.4636 \mathrm{x}$ & 6.0686 \\
\hline M & 134.9782 & 7.6689 & $4.4636 x$ & 14.6566 \\
\hline $\mathrm{DM}$ & 135.0010 & NA & $4.4636 \mathrm{x}$ & NA \\
\hline
\end{tabular}

In the previous examples, it can be observed that the proposed method using the Milstein scheme obtains good results by decreasing the value of the attenuating factor $\delta$, as shown in Table 3 with an exception in the subcritical reactivity for $\delta=0.5$. For critical reactivity, the best approximation to the deterministic value is achieved by the proposed scheme in comparison with the methods reported in the literature as can be seen in Table 5 .

The fourth example considers a group of precursors for a TRIGA reactor with the following physical parameters: Reactivity $\rho=300 \mathrm{pcm}$, neutron generation time $\Lambda=0.0001 \mathrm{sec}$, decay constant $\lambda_{1}=0.077\left(\mathrm{~s}^{-1}\right)$, fraction of delayed neutron precursors $\beta=0.0079$, average of neutrons generation per fission event $v=2.432$, external source of neutrons $q(t)=10000$, initial condition $\mathrm{n}(0)=0, \mathrm{C}(0)=0$. This example is carried out with 100 iterations in a time interval of $[0,0.1] \mathrm{sec}$, using 10000 Wiener processes. For this example, the time step has been increased by a factor of $10^{4}$ with respect to the value with reported by Ayyoubzadeh and Vosoughi (2014), evidencing how the proposed method using the Milstein scheme provides good approximations as seen in Table 6 and 7.

In this last example, which is presented in (Ayyoubzadeh and Vosoughi, 2014) and carried out only by three methods (SPCA, MC and SSPK), the proposed scheme in this study is the better approaching to the expected values of the study variables, in comparison with the deterministic model, even when the time step has been modified to a larger one. The change in neutron 


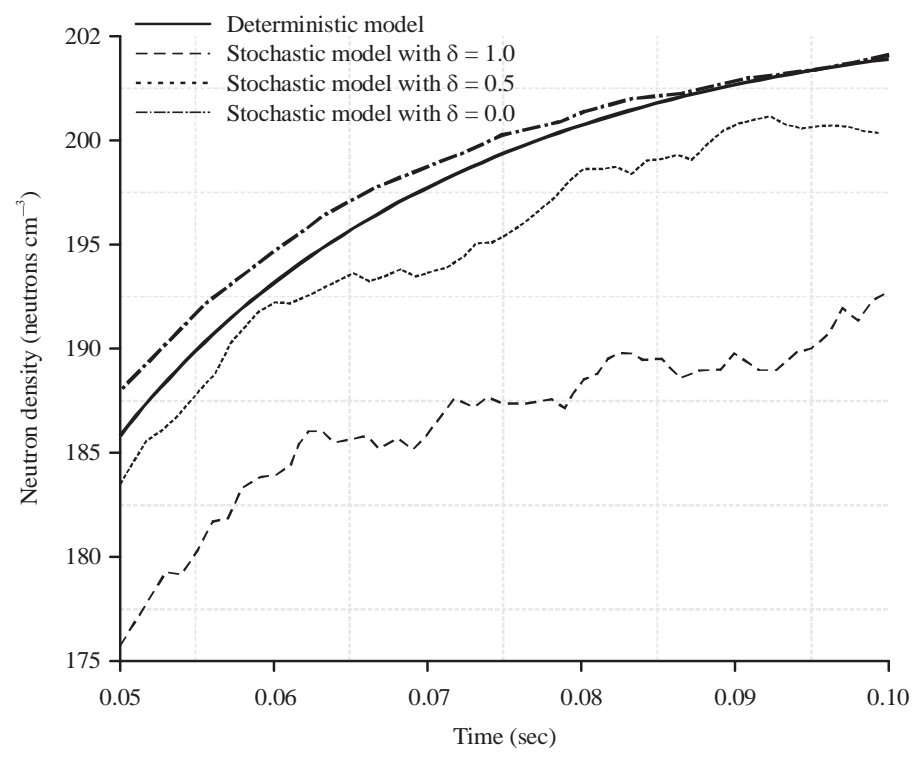

Fig. 2: Neutron density for the stochastic model for the different values of and the Deterministic Model (DM) with reactivity

Table 6: Stochastic model with different values of and Deterministic Model (MD) for the TRIGA reactor

\begin{tabular}{lllll} 
Parameters & $\mathrm{E}[\mathrm{n}(0.1 \mathrm{~s})]$ & $\sigma[\mathrm{n}(0.1 \mathrm{~s})]$ & $\mathrm{E}[\mathrm{C}(0.1 \mathrm{~s})]$ & $\sigma[\mathrm{C}(0.1 \mathrm{~s})]$ \\
\hline$\delta$ & & & & 749.4708 \\
1 & 192.7425 & 191.5812 & 1.1964 & 531.8888 \\
0.5 & 200.1817 & 134.9196 & 1.2524 & 102.8441 \\
0 & 204.0507 & 18.6307 & 1.2827 & NA \\
DM & 203.9027 & $\mathrm{NA}$ & 1.2861 & \\
\hline
\end{tabular}

Table 7: Comparison of results, proposed scheme, reported in the literature and deterministic model for the TRIGA reactor

\begin{tabular}{lllll}
\hline Methods & $\mathrm{E}[\mathrm{n}(0.1 \mathrm{~s})]$ & $\sigma[\mathrm{n}(0.1 \mathrm{~s})]$ & $\mathrm{E}[\mathrm{C}(0.1 \mathrm{~s})]$ & $\sigma[\mathrm{C}(0.1 \mathrm{~s})]$ \\
\hline SPCA & 204.5200 & 174.0300 & $1.2940 \mathrm{x}$ & 620.6800 \\
MC & 199.1500 & 152.6300 & $1.2545 \mathrm{x}$ & 613.9400 \\
SSPK & 208.1400 & 174.3000 & $1.2932 \mathrm{x}$ & 622.1200 \\
M & 204.0507 & 18.6307 & 1.2827 & 102.8441 \\
DM & 203.9027 & $\mathrm{NA}$ & $1.2861 \mathrm{x}$ & NA \\
\hline
\end{tabular}

density and its standard deviation as the attenuating factor changes is seen in Fig. 2 as having the same behavior as in the previous three numerical experiments.

In this study, various numerical experiments have been presented using different initial conditions, precursor groups, time steps, constant reactivities and $\delta$ factor values. Milstein's iterative scheme is used for the first time in literature, producing good average value results, with respect to other reported schemes. When using the attenuating factor $\delta$, the standard deviation of the study variables is considerably reduced, however, this modification is not sufficiently strong as those presented in (Nahla and Edress, 2016) and in (Suescun et al., 2018) modifying the matrix of variances and the matrix of expected values, respectively. This is due to the fact that the method used in the present study only modifies a matrix element, while in the aforementioned two works, more terms are modified.

\section{CONCLUSION}

In this study, the equations of stochastic point kinetics have been presented and solved numerically using the Milstein scheme. The random variables on the part of the stochastic model with respect to the deterministic model, model in a more real way the behavior of the neutron population in the reactor. The numerical results obtained by the proposed scheme using the approximation of the first derivative of the variances matrix and with the attenuating factor $\delta$, present good approximations to the deterministic model, as well as a notable decrease of standard deviation. The results are in agreement with the other methods reported in the literature. Thus, it is determined that the iterative scheme proposed in this research can be used in the solution of stochastic point kinetics. 


\section{ACKNOWLEDGEMENTS}

This study was carried out thanks to the academic and financial support from the Computational Physics Research Group, the applied physics research group (FIASUR) and the physics department at the Surcolombian University, Neiva, Colombia.

\section{REFERENCES}

Ayyoubzadeh, S.M. and N. Vosoughi, 2014. An alternative stochastic formulation for the point reactor. Ann. Nucl. Energy, 63: 691-695.

Da Silva, M.W., R. Vasques, B.E. Bodmann and M.T. Vilhena, 2016. A nonstiff solution for the stochastic neutron point kinetics equations. Ann. Nucl. Energy, 97: 47-52.

Hayes, J.G. and E.J. Allen, 2005. Stochastic point-kinetics equations in nuclear reactor dynamics. Ann. Nucl. Energy, 32: 572-587.

Kloeden, P. and E. Platen, 1992. Numerical Solution of Stochastic Differential Equations (Applications of Mathematics). 2nd Edn., Springer, New York, USA., ISBN-13: 9780387540627, Pages: 632.
Le Gall, J.F., 2016. Brownian Motion, Martingales and Stochastic Calculus. Vol. 274, Springer, Heidelberg, Germany, ISBN:978-3-319-31088-6, Pages: 273.

Nahla, A.A. and A.M. Edress, 2016a. Analytical exponential model for stochastic point kinetics equations via. eigenvalues and eigenvectors. Nucl. Sci. Tech., 27: 19-27.

Nahla, A.A. and A.M. Edress, 2016.b Efficient stochastic model for the point kinetics equations. Stochastic Anal. Appl., 34: 598-609.

Ray, S.S. and A. Patra, 2013. Numerical solution of fractional stochastic neutron point kinetic equation for nuclear reactor dynamics. Ann. Nuclear Energy, 54: 154-161.

Ray, S.S., 2012. Numerical simulation of stochastic point kinetic equation in the dynamical system of nuclear reactor. Ann. Nucl. Energy, 49: 154-159.

Stacey, W.M., 2018. Nuclear Reactor Physics. 3rd Edn., Wiley-VCH, Weinheim, Germany, ISBN:978-3-527-41366-9, Pages: 766.

Suescun-Diaz, D., Y.M. Oviedo-Torres and L.E. Giron-Cruz, 2018. Solution of the stochastic point kinetics equations using the implicit Euler-Maruyama method. Ann. Nucl. Energy, 117: 45-52. 